Col 27

MITOMYCIN C PLUS 5-FLUOROURACIL VERSUS PLASMAPHERESIS AND THE SAME CHEMOTHERAPY IN METASTATIC COLORECTAL CANCER: A PROSPECTIVE RANDOMIZED TRIAL

J.-H. Beyer, R. Bätge, W. Rauschning, P. SchuffWerner, H. Rauschecker and H.-J. Peiper

A pilot study in pts with metastatic colorectal cancer, treated with mitomycin $C 15 \mathrm{mg} / \mathrm{m}^{2} \mathrm{i} . \mathrm{v}$. bolus day 1 and 5 -fluorouracil $30 \mathrm{mg} / \mathrm{kg} /$ day continuously infused days 1-5 repeated every 6 weeks, showed partial responses in 6 of 15 patients $\left(40 \frac{\circ}{0}\right)$. Plasmapheresis in 23 pts with chemotherapy-resistant colorectal cancer was able to overcome the drug resistance in 15 of 23 pts. Here we report on a randomized prospective trial comparing the two treatment modalities. $16 \mathrm{pts}$ were randomized into group A (CT with mitomycin $\mathrm{C}$ and 5-FU, dose as above) and 16 into group $B$ (plasmapheresis and CT). The results are shown in table 1 (remission duration in weeks) :

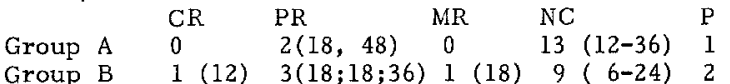

The time under therapy was $20.8+1-11.4$ and $16.6+1-$ 8.7 weeks $(p=0.126)$, and the survival time after cessation of therapy $4.8+1-2.6$ and $6.2+/-4.2 \quad(p=0.159)$ months. Three patients of each group are still alive: $12+, 15+, 17+$ months in $A$ and $7+, 10+, 22+$ months in $B$. The main side-effects are in group $A$ and $B$ : anaemia $5 x / 2 x$, leukopenia $6 x / 3 x$, thrombocytopenia $6 x / 3 x$, stomatitis $2 x / 2 x$, lung insufficiency $4 x / 3 x$, renal insufficiency $0 \mathrm{x} / 3 \mathrm{x}$ (tumour progression), HUS $1 \mathrm{x} / 0 \mathrm{x}$.

According to these results with a limited number of pts the regimen $B$ neither initiates more clinical responses, nor prolongs the response duration and overall survival.

Abt. Hämatologie/Onkologie, Medizinische Universitätsklinik, Robert-Koch-Str. 40, D-3400 Göttingen

\section{Col 28}

INTRAPORTAL CYTOSTATIC THERAPY VIA THE UMBILI CAL VEIN OF LIVER METASTASES FOLLOWING COLORECTAL CARCINOMA

H. Strosche, D. Schlenkhoff, K.-D. Lindecken

Since 0ct. 198415 patients with diffuse metastases of the liver following colorectal carcinoma have been treated by loco-regional intraportal chemotherapy. Study includes 10 men $(60,9 \pm 7,7$ years $)$ and 5 women $(58 \pm 10,9$ years $)$. After resection of the colorectal tumor, a Port-A-Cath system was implanted via the umbilical vein. Ten days after implantation and following angiography via the Port-A-Cath, cytostatic drugs were given on a 28 day cycle using $5-\mathrm{FU}\left(750 \mathrm{mg} / \mathrm{m}^{2} / 24 \mathrm{~h}\right)$ over 4 days as we 11 as a solitary dose of Mitomycin $\left(8 \mathrm{mg} / \mathrm{m}^{2}\right)$. Therapy was controlled at regular intervals by CEA, CT, sonography and portography. Apart from two dislocations which were adjustable, no further Port-A-Cath complications were observed. The totally implantable infusion system and the missing systemic toxicity improved the quality of 7 ife.

Up to now 5 patients ( 4 men, 1 woman) have died under therapy (average survival-time: $3,9 \pm 2,0$ months). These patients showed a 50-60\% metastases volume as seen in the approximatively quantitative determination of metastases volume in CT at begin of therapy: Indication of cytostasis and its effectivity depend on the determination of metastases quantity volume using CT. This method allows not only a comparison of various therapy concepts but also the e.stimation of metastases volume and corresponding the expected survival time.

Chirurgische Universitätskiinik der Ruhr-Universität Bochum - Marienhospital Herne, Hölkeskampring 40, D-4690 Herne 1

\section{Col 29}

RANDOMTZED MULTICENTER TRIAL OF SEOUENTIAL METHOTREXATE (MTX) AND 5-FLUOROURACIL(FU) VS FU ALONE IN METASTATIC COLORECTAL CARCINOMA(CRC).

R. Herrmann, A.Knuth, U.Kleeberg, R.Middecke, U.Abel for the Arbeitsgemeinschaft Internistische Onkologie.

In a recent phase II trial we have shown a favorable response rate for sequential MTX/FU in CRC (JCO 2: 591). Since $7 / 83166$ patients(pts) with measurable metastatic CRC have been prospectively randomized to receive either MTX/FU(MTX $150 \mathrm{mg} / \mathrm{m}^{2}$ iv push followed by MTX $150 \mathrm{mg} / \mathrm{m}^{2}$ iv infusion over 4 hrs, FU $900 \mathrm{mg} / \mathrm{m}^{2} 7$ hrs after start of MTX and leucovorin $15 \mathrm{mg}$ po q 6 hrs $x$ 8 beginning $24 \mathrm{hrs}$ after MTX) or FU alone (FU $450 \mathrm{mg} / \mathrm{m}^{2}$ iv push qdx5). MTX/FU was repeated q 2 weeks $x 3$, then q 3 weeks. FU cycles were given q 3 weeks. Eligibility criteria included ECOG performance status(PS) $0-3$, age $<76$, creatinine clearance $>70 \mathrm{ml} / \mathrm{min}$, absence of major effusion, no prior chemotherapy. Survival was the primary study endpoint. The two groups are comparable with respect to age, PS, prior weight loss, localisation of the primary, histologic grade and disease-free interval. At the present time 126 pts are evaluable, 73 have been followed to time of death. Response rate for MTX/FU is $28 \%$ with $3 \mathrm{CRs}$ and $14 \mathrm{PRs}$. For FU alone response ratr. is $15 \%$ ( 1 CR, 9 PRs). This ${ }_{2}$ difference indicates a trend in favor of MTX/FU ( $p=0.08, x^{2}$-test). Median duration of response was $8.2 \mathrm{mo}(M T X / F U)$ and 7.5 mo (FU) resp. Curves of overall survival are almost identical with a median of $10.7 \mathrm{mo}$ (MTX/FU) and $12.8 \mathrm{mo}$ (FU) resp. Lukocytopenia and stomatitis were significantly more common in pts receiving FU alone, while other side effects were usually mild and not different. In conclusion: This schedule of sequential MTX/FU seems to be marginally more effective and less toxic than FU alone in inducing remissions in CRC. However, the results of this trial do not suggest a survival benefit for pts receiving MTX/FU.

Klinikum Charlottenburg, Freie Universität, 1000 Berlin 19 Germany.

\section{Col 30}

LONG-TIME INFUSION OF SEQUENTTAL METHOTREXATE AND 5-FLUOROURACIL IN THE TREATMENT OF ADVANCED COLORECTAL CANCER. E.J.BORGHARDT, ST.DÖLL, R. FOCK. U.PLENER

It has already been demonstrated in clinical trials that sequential use of methotrexate (MTX) and 5-Fluorouracil (5-FH) may result in synergistic tumor cell kill. Recent studies have shown ar increasing overali response rate in colon cancer patients with the application of a high-dose of MTX/5-FU in the sequence, compared to the commonily accepted resporise rate of $15 \%-20 \%$ with $5-\mathrm{Fll}$ treatnent alone. In vitro data suggested a superior synergistic effect with Ionger time intervals for the sequence MTX/5-FU.

Regarding the quite substantial toxicity rate with high-dose MTX/5-Fy it was necessary to investigate the offects of a modified combination with prolanged time intervals and the application of low doses. 24 patients with a median age of 64 years (range $46-76$ years) entered the study so far. 6 were pretreated by radiation, 2 with 5 -Fu monotherapy. Of the 20 currently evaluable patients 11 had liver metastases, 7 had lung metastases, 5 had lymphrode metastases and 11 abdominal or pelvic masses. The treatment cansisted of $M T X 50 \mathrm{mg} / \mathrm{m}^{2}$ i.v. bolus injestion, followed by MIX $50 \mathrm{mg} / \mathrm{m}^{2}$ as a 24 hour infusion and here after $600 \mathrm{mg} / \mathrm{m}^{2} 5-\mathrm{fl}$ as a 6 hour infusion. Leucovorin rescue $22,5 \mathrm{mg}(1,5$ tablets) was given to all patients every 6 hours for eight doses after finishing 5-FU.

The first two treatment cycles were repeated every two weeks, then followed by three weeks intervals until progression.

A minimum of three treatment cycleswas required for evaluation of response using standard criteria. Of the 20 currently evaluable patients $4(20 \%)$ achieved a partial response (PR) and $9(45 \%)$, had stable disease (NC). 7 (35\%) showed a progressive disease. Median duration of response ( $P R$ and NC) was 10,5 months. Median survial of all patients was 9,0 months so far, but only 4,3 months for patients with progressive disease.

No toxicity was observed in the patients, especially no stomatitis, no hairloss, no vomiting. There was only a mild nausea in $10 \%$ of the patients. Significant myelosuppression was not regarded. This data from an angoing study is promising, updated results will be presented.

Abtlg. Onkologie/Hämatologie, Medizinische Klinik Bad Münder Deisterallee 36, D - 3252 Bad Müder 1. 